\title{
Deduction of Novel Genes Potentially Involved in Osteoblasts of Rheumatoid Arthritis Using Next-Generation Sequencing and Bioinformatic Approaches
}

\author{
Yi-Jen Chen ${ }^{1,2,3}$, Wei-An Chang ${ }^{1,4}$, Ya-Ling Hsu ${ }^{5}$, Chia-Hsin Chen ${ }^{2,3,6,7, *}$ and Po-Lin Kuo ${ }^{1,8, *}$ \\ 1 Graduate Institute of Clinical Medicine, College of Medicine, Kaohsiung Medical University, Kaohsiung 807, \\ Taiwan; chernkmu@gmail.com (Y.-J.C.); 960215kmuh@gmail.com (W.-A.C.) \\ 2 Department of Physical Medicine and Rehabilitation, Kaohsiung Medical University Hospital, \\ Kaohsiung 807, Taiwan \\ 3 Department of Physical Medicine and Rehabilitation, Kaohsiung Municipal Ta-Tung Hospital, \\ Kaohsiung 801, Taiwan \\ 4 Division of Pulmonary and Critical Care Medicine, Kaohsiung Medical University Hospital, \\ Kaohsiung 807, Taiwan \\ 5 Graduate Institute of Medicine, College of Medicine, Kaohsiung Medical University, Kaohsiung 807, Taiwan; \\ hsuyl326@gmail.com \\ 6 Department of Physical Medicine and Rehabilitation, School of Medicine, College of Medicine, \\ Kaohsiung Medical University, Kaohsiung 807, Taiwan \\ 7 Orthopaedic Research Center, Kaohsiung Medical University, Kaohsiung 807, Taiwan \\ 8 Institute of Medical Science and Technology, National Sun Yat-Sen University, Kaohsiung 804, Taiwan \\ * Correspondence: chchen@kmu.edu.tw (C.-H.C.); kuopolin@seed.net.tw (P.-L.K.); \\ Tel.: +886-7-312-1101 (ext. 5962) (C.-H.C.); +886-7-312-1101 (ext. 2512-33) (P.-L.K.)
}

Received: 15 October 2017; Accepted: 6 November 2017; Published: 11 November 2017

\begin{abstract}
The role of osteoblasts in peri-articular bone loss and bone erosion in rheumatoid arthritis (RA) has gained much attention, and microRNAs are hypothesized to play critical roles in the regulation of osteoblast function in RA. The aim of this study is to explore novel microRNAs differentially expressed in RA osteoblasts and to identify genes potentially involved in the dysregulated bone homeostasis in RA. RNAs were extracted from cultured normal and RA osteoblasts for sequencing. Using the next generation sequencing and bioinformatics approaches, we identified 35 differentially expressed microRNAs and 13 differentially expressed genes with potential microRNA-mRNA interactions in RA osteoblasts. The 13 candidate genes were involved mainly in cell-matrix adhesion, as classified by the Gene Ontology. Two genes of interest identified from RA osteoblasts, A-kinase anchoring protein 12 (AKAP12) and leucin rich repeat containing 15 (LRRC15), were found to express more consistently in the related RA synovial tissue arrays in the Gene Expression Omnibus database, with the predicted interactions with miR-183-5p and miR-146a-5p, respectively. The Ingenuity Pathway Analysis identified AKAP12 as one of the genes involved in protein kinase A signaling and the function of chemotaxis, interconnecting with molecules related to neovascularization. The findings indicate new candidate genes as the potential indicators in evaluating therapies targeting chemotaxis and neovascularization to control joint destruction in RA.
\end{abstract}

Keywords: rheumatoid arthritis; bone erosion; osteoblasts; next-generation sequencing; bioinformatics; microRNA; messenger RNA 


\section{Introduction}

Rheumatoid arthritis (RA) is an autoimmune disease characterized by systemic inflammation, presence of autoantibodies, and targeted synovitis, affecting approximately $0.5-1 \%$ of population [1]. Articular manifestation of inflammatory arthritis is the hallmark of RA and a major determinant of the disease activity [2]. Numerous cell types are involved in the pathophysiology of RA, including immune cells like T cell, B cells and macrophages, synoviocytes, and chondrocytes $[3,4]$. Synoviocytes and chondrocytes are cell types within the joint dominantly affected by RA. Activated synovial fibroblasts within the inflamed synovium have altered morphology and behavior, and attach directly to cartilage and release matrix degradation enzymes, leading to the destruction of cartilage tissue $[1,5,6]$. They also interact indirectly with adjacent macrophages through the release of receptor activator of nuclear factor $\mathrm{KB}$ ligand (RANKL) and mediate the differentiation of macrophage precursors into osteoclasts [6,7].

Bone erosion is a characteristic feature of affected joints in RA, known to be triggered mainly by synovitis, producing pro-inflammatory cytokines and RANKL [8]. Within the inflamed joint structure, the destructive process by the pannus, a structure formed by proliferative synovium containing infiltrates of immune cells, proliferative vessels, and increased osteoclasts, leads to bone erosion particularly at the synovium-bone interface where the pannus invades [9]. Through the direct contact of the invading pannus to the bone and increased angiogenesis within the pannus structure, the capacity of the synovial fibroblasts to damage structures within the joint has been widely proposed [8-11]. Together with synovial fibroblasts and immune cells, the critical role of osteoclasts in the disrupted bone homeostasis under pathological condition such as RA is being studied. The imbalance of bone homeostasis in RA leads to peri-articular bone loss, which usually precedes bone erosion and further progression of joint destruction [12].

While osteoclasts are the major cells responsible for bone loss and bone erosion in RA, the impaired differentiation and function of osteoblasts have been proposed in recent studies, and inflammatory tissue in RA may impair osteoblast activity, which respond differently from osteoblasts of osteoarthritic condition [12-15]. The precursors of immune cells are formed and maintained in the bone marrow, where osteoclasts and osteoblasts reside and act to maintain a balanced bone remodeling; therefore, research on the interplay between the immune system and the skeletal system has emerged to gain more knowledge on the novel field termed osteoimmunology [8,16,17].

MicroRNAs (miRNAs) are non-coding single strand RNAs consisting of 20-22 nucleotides, acting primarily on the $3^{\prime} \mathrm{UTR}$ of mRNAs to regulate gene expressions through a post-transcriptional manner [18]. These small non-coding RNAs participate in the regulation of numerous cellular processes and dysregulation of miRNAs are associated with various diseases [19]. The role of miRNA regulation in bone diseases has been reported, including osteoporosis and arthritis that are associated with altered bone homeostasis $[20,21]$. The study of gene associations using the next generation sequencing (NGS) technique and bioinformatics approaches has evolved, providing high-throughput genomic profiling and further understanding and analysis of functional annotations of identified genes and/or miRNAs [22,23]. In this study, we used various bioinformatics tools and databases to assist in identifying potential miRNA-mRNA interactions in osteoblasts of RA population, including miRmap [24], Gene Expression Omnibus (GEO) [25], Ingenuity ${ }^{\circledR}$ Pathway Analysis (IPA) [26], and Database for Annotation, Visualization and Integrated Discovery (DAVID) [27].

The role of osteoblasts in the development of peri-articular bone loss and limited repair of bone erosion in RA has received much attention, and miRNAs are hypothesized to play critical roles in the regulation of osteoblast function in RA. The aim of our current study is to explore novel miRNAs differentially expressed in osteoblasts of RA bone and to identify genes potentially involved in the dysregulated bone homeostasis in RA. Using the NGS for genomic profiling and various bioinformatics approaches, we expect the findings will provide novel insights into potential therapeutic targets that contribute to better control of RA disease activity. 


\section{Results}

2.1. Identification of Differentially Expressed miRNAs and Potential miRNA-mRNA Interactions between Osteoblasts of Normal and Rheumatoid Arthritis Bones

To identify differentially expressed miRNAs and mRNAs between osteoblasts of normal and RA bones, and potential miRNA-mRNA interactions involved in the inflammatory process and bone homeostasis, we simultaneously performed RNA-seq and small RNA-seq by NGS of normal osteoblasts and RA osteoblasts. There were 35 miRNAs with $>2.0$-fold change and $>10$ reads per million (RPM) of either origin of osteoblasts identified. Sixteen up-regulated and 19 down-regulated miRNAs in RA osteoblasts compared to normal osteoblasts were identified, as listed in Table 1. Figure 1A presents the heat map analysis of the 35 differentially expressed miRNAs with z-score values. In addition, we found 434 protein-coding genes with $>2$.0-fold change and $>0.3$ fragments per kilobase of transcript per million (FPKM), where 199 genes were up-regulated and 235 genes were down-regulated in RA osteoblasts, compared to normal osteoblasts. To determine potential miRNA-mRNA interactions in normal and RA osteoblasts, we first analyzed putative targets of the 35 miRNAs by miRmap database, and selected targets with miRmap score of more than 99.0. The results yielded 435 targets (520 interactions) of 16 up-regulated miRNAs and 391 targets (477 interactions) of 19 down-regulated miRNAs. We then matched these predicted targets by up-regulated (down-regulated) miRNAs to down-regulated (up-regulated) genes from the 434 protein-coding genes selected. By Venn diagram analysis, we identified 13 genes (eight down-regulated genes and five up-regulated genes) with potential miRNA-mRNA interactions in RA osteoblast (Figure 1B).

A

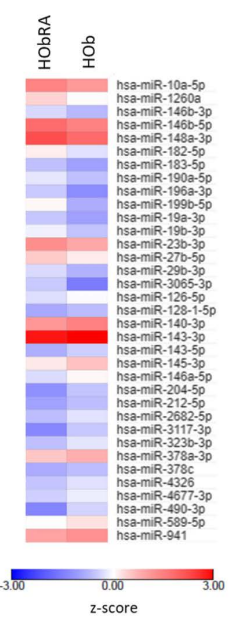

B

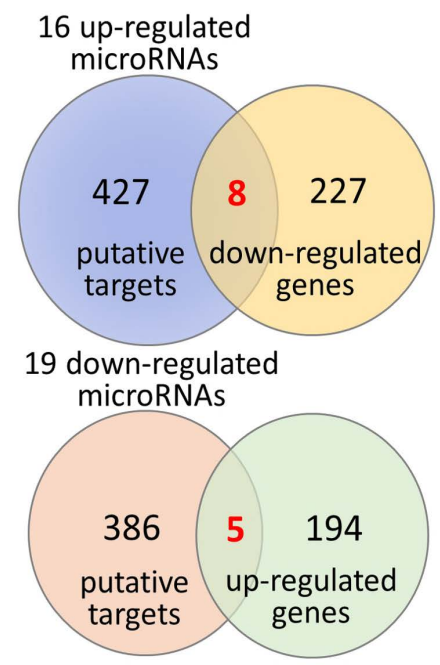

Figure 1. Identification of differentially expressed microRNAs and potential microRNA-mRNA interactions in rheumatoid arthritis primary osteoblasts. (A) The next generation sequencing (NGS) identified 35 differentially expressed microRNAs (thresholds of $>2.0$-fold change and reads per million $(R P M)>10$ ) in rheumatoid arthritis (RA) osteoblasts, compared to normal osteoblasts. The heat map analysis with z-score values is shown here. (B) The 16 up-regulated and 19 down-regulated microRNAs predicted 435 and 391 putative targets, respectively, using the miRmap database with selection threshold of miRmap score $\geq 99.0$. Additionally, 434 protein-coding genes with $>2.0$-fold change and $>0.3$ fragments per kilobase of transcript per million (FPKM) were identified from the NGS, where 199 genes were up-regulated and 235 genes were down-regulated in RA osteoblasts. The putative targets of up-regulated (down-regulated) microRNAs were matched to the down-regulated (up-regulated) protein-coding genes by the Venn diagram analysis. Finally, thirteen genes (eight down-regulated and five up-regulated) with potential miRNA-mRNA interactions were identified. 
Table 1. Differentially expressed miRNAs in normal and rheumatoid arthritis (RA) osteoblasts.

\begin{tabular}{|c|c|c|c|c|}
\hline microRNA & Precursor & $\begin{array}{l}\text { HObRA Seq } \\
\text { (Norm) }\end{array}$ & HOb Seq (Norm) & Fold Change \\
\hline hsa-miR-3065-3p & hsa-mir-3065 & 14.08 & 1.26 & 11.17 \\
\hline hsa-miR-199b-5p & hsa-mir-199b & 55.42 & 7.36 & 7.53 \\
\hline hsa-miR-196a-3p & hsa-mir-196a-2 & 14.34 & 2.31 & 6.21 \\
\hline hsa-miR-148a-3p & hsa-mir-148a & $12,452.28$ & 4404.25 & 2.83 \\
\hline hsa-miR-19a-3p & hsa-mir-19a & 13.43 & 4.83 & 2.78 \\
\hline hsa-miR-19b-3p & hsa-mir-19b-1 & 35.6 & 14.08 & 2.53 \\
\hline hsa-miR-29b-3p & hsa-mir-29b-1 & 22.17 & 8.83 & 2.51 \\
\hline hsa-miR-23b-3p & hsa-mir-23b & 1117.61 & 471.84 & 2.37 \\
\hline hsa-miR-182-5p & hsa-mir-182 & 67.94 & 28.69 & 2.37 \\
\hline hsa-miR-146b-5p & hsa-mir-146b & 4319.58 & 1843 & 2.34 \\
\hline hsa-miR-183-5p & hsa-mir-183 & 11.08 & 4.83 & 2.29 \\
\hline hsa-miR-10a-5p & hsa-mir-10a & 1708.04 & 752.73 & 2.27 \\
\hline hsa-miR-1260a & hsa-mir-1260a & 126.48 & 56.64 & 2.23 \\
\hline hsa-miR-190a-5p & hsa-mir-190a & 28.56 & 13.24 & 2.16 \\
\hline hsa-miR-146b-3p & hsa-mir-146b & 21.38 & 10.61 & 2.02 \\
\hline hsa-miR-27b-5p & hsa-mir-27b & 160.78 & 80.29 & 2.00 \\
\hline hsa-miR-490-3p & hsa-mir-490 & 1.43 & 21.12 & -14.77 \\
\hline hsa-miR-3117-3p & hsa-mir-3117 & 1.56 & 15.87 & -10.17 \\
\hline hsa-miR-204-5p & hsa-mir-204 & 2.22 & 14.82 & -6.68 \\
\hline hsa-miR-143-3p & hsa-mir-143 & $54,069.61$ & $16,0924.3$ & -2.98 \\
\hline hsa-miR-143-5p & hsa-mir-143 & 6.39 & 18.92 & -2.96 \\
\hline hsa-miR-212-5p & hsa-mir-212 & 4.3 & 12.51 & -2.91 \\
\hline hsa-miR-323b-3p & hsa-mir-323b & 10.95 & 31.53 & -2.88 \\
\hline hsa-miR-2682-5p & hsa-mir-2682 & 10.3 & 29.63 & -2.88 \\
\hline hsa-miR-146a-5p & hsa-mir-146a & 22.69 & 64.84 & -2.86 \\
\hline hsa-miR-145-3p & hsa-mir-145 & 77.45 & 212.17 & -2.74 \\
\hline hsa-miR-140-3p & hsa-mir-140 & 814.97 & 1900.06 & -2.33 \\
\hline hsa-miR-4326 & hsa-mir-4326 & 12.65 & 28.69 & -2.27 \\
\hline hsa-miR-4677-3p & hsa-mir-4677 & 16.69 & 37.1 & -2.22 \\
\hline hsa-miR-128-1-5p & hsa-mir-128-1 & 5.35 & 11.66 & -2.18 \\
\hline hsa-miR-378a-3p & hsa-mir-378a & 174.47 & 376.1 & -2.16 \\
\hline hsa-miR-126-5p & hsa-mir-126 & 23.47 & 50.02 & -2.13 \\
\hline hsa-miR-378c & hsa-mir-378c & 5.87 & 12.4 & -2.11 \\
\hline hsa-miR-941 & hsa-mir-941-1 & 516.36 & 1049.39 & -2.03 \\
\hline hsa-miR-589-5p & hsa-mir-589 & 49.16 & 98.36 & -2.00 \\
\hline
\end{tabular}

\subsection{The 13 Candidate Genes Were Involved in the Cell Matrix Adhesion and Related Molecular Functions}

The 13 candidate genes identified from normal and RA osteoblasts were analyzed by DAVID database to determine the functional annotations of these genes. Setting the EASE threshold at 1.0, the Gene Ontology classified these genes to be involved in cell-matrix adhesion and G-protein coupled receptor signaling pathway in the domain of biological process. In the domain of molecular function, the genes were involved in the bindings of collagen, protease, heparin and protein, as shown in Figure 2A. In the domain of cellular component, the genes were mostly active in the extracellular exosome, cytoskeleton, cytoplasm, and plasma membrane (Figure 2B). The KEGG pathway identified CREB5, BDKRB2 and COL5A3 to be involved in the CGMP-PKG and PI3K-Akt signaling pathways. 
A

GO_MOLECULAR FUNCTION

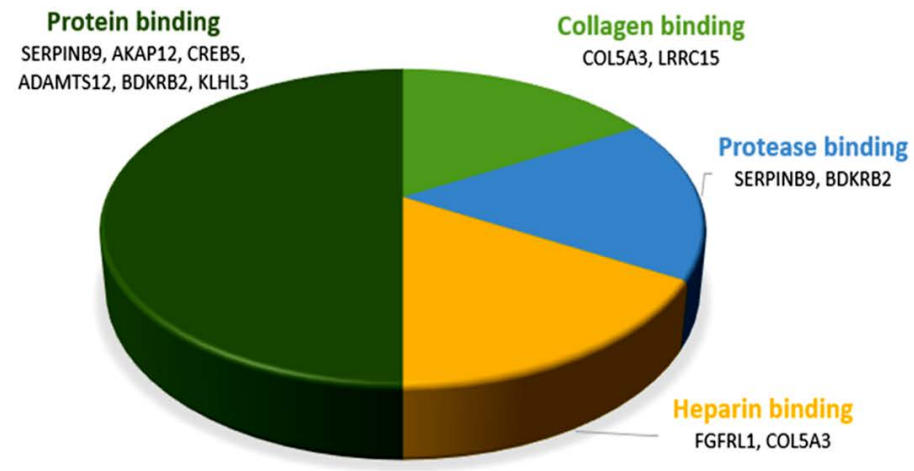

B

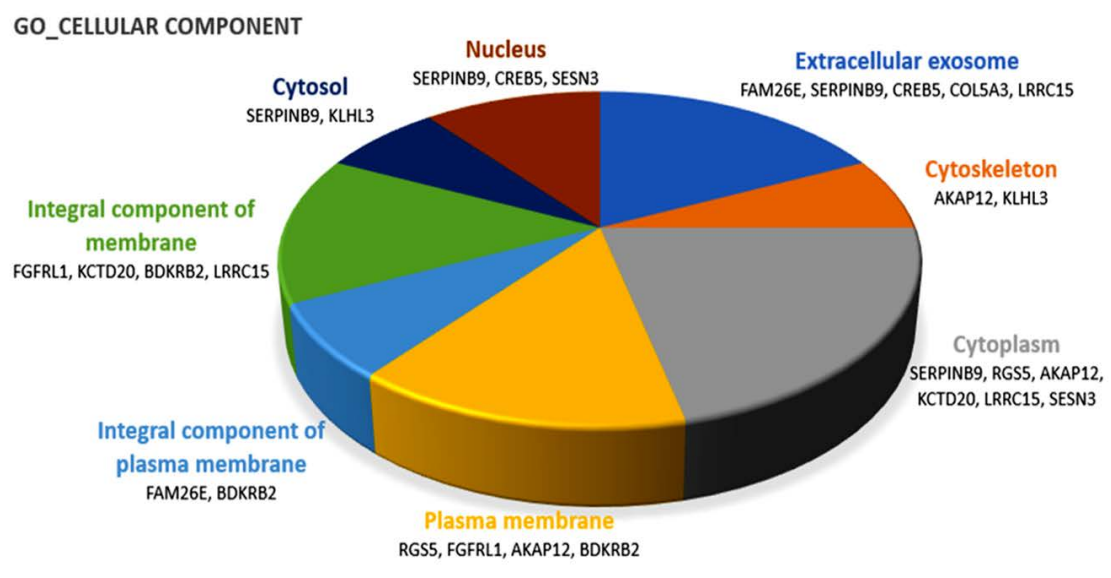

Figure 2. Gene ontology terms involved in the 13 candidate genes of rheumatoid arthritis primary osteoblasts. Using the functional annotation analysis in the DAVID database, the 13 candidate genes were classified by terms of the Gene Ontology in: the molecular function domain (A); and the cellular component domain (B). The related genes are listed below each term. The selected criteria for functional annotation analysis was EASE $=1.0$.

2.3. Analysis of Candidate Genes from Normal and Rheumatoid Arthritis (RA) Osteoblasts in Gene Expression Omnibus (GEO) Database and Identification of Potential Molecular Signatures in RA Joint Microenvironment

The 13 candidate genes with potential miRNA-mRNA interactions identified from normal and RA osteoblasts are listed in Table 2. To determine the involvement of these genes in the joint microenvironment of RA patients, we searched in the GEO database for RA related arrays. There were no arrays comparing osteoblasts or bones of normal and RA patients available in the GEO database. However, we found five arrays comparing synovial tissues of normal and RA patients (GSE1919, GSE55235, GSE55475, GSE7307 and GSE77298), one array comparing synovial fibroblasts isolated from synovial tissues of normal and RA patients (GSE29746) and two arrays comparing synovial macrophages of normal and RA patients (GSE10500 and GSE97779). We analyzed the expression values of the 13 candidate genes identified from normal and RA osteoblasts in these RA related arrays and found two genes that were expressed in the same direction in RA synovial tissues more consistently. As shown in Table 3, the up-regulated LRRC15 in RA osteoblasts was found up-regulated in four out of the five arrays of synovial tissues; the down-regulated AKAP12 in RA osteoblasts was found down-regulated in four out of the five arrays of synovial tissues; and up-regulated in one array of synovial macrophages. Additionally, the up-regulated CREB5 and down-regulated KCTD20 in RA osteoblasts were observed to express in the same direction in arrays of synovial macrophages. The expression values of the 13 candidate genes in the representative array dataset (GSE77298) are shown in Figure 3. 
Table 2. Candidate genes identified from putative targets of microRNAs and differentially expressed genes between normal and RA osteoblasts.

\begin{tabular}{ccc}
\hline Gene Symbol & Gene Name & $\begin{array}{c}\text { Fold-Change } \\
\text { (HObRA/HOb) }\end{array}$ \\
\hline BDKRB2 & bradykinin receptor B2 & 3.20 \\
CREB5 & cAMP responsive element binding protein 5 & 3.11 \\
FGFRL1 & fibroblast growth factor receptor-like 1 & 2.76 \\
LRRC15 & leucine rich repeat containing 15 & 5.85 \\
SESN3 & sestrin 3 & 2.17 \\
ADAMTS12 & ADAM metallopeptidase with thrombospondin type 1 motif 12 & 0.37 \\
AKAP12 & A-kinase anchoring protein 12 & 0.39 \\
COL5A3 & collagen, type V, alpha 3 & 0.07 \\
FAM26E & family with sequence similarity 26 member E & 0.46 \\
KCTD20 & potassium channel tetramerization domain containing 20 & 0.32 \\
KLHL3 & kelch like family member 3 & 0.38 \\
RGS5 & regulator of G-protein signaling 5 & 0.11 \\
SERPINB9 & serpin family B member 9 & 0.32 \\
\hline
\end{tabular}

Table 3. Analysis of 13 candidate genes in RA related arrays in Gene Expression Omnibus (GEO) datasets.

\begin{tabular}{|c|c|c|c|c|c|c|c|c|}
\hline Accession \# & GSE7307 & GSE55475 & GSE77298 & GSE55235 & GSE1919 & GSE29746 & GSE10500 & GSE97779 \\
\hline Specimen & \multicolumn{5}{|c|}{ Synovial tissue } & Fibroblast & \multicolumn{2}{|c|}{ Synovial macrophage } \\
\hline \multirow{2}{*}{ Numbers } & N/RA & N/RA & N/RA & N/RA & N/RA & N/RA & N/RA & $\mathrm{N} / \mathrm{RA}$ \\
\hline & $5 / 5$ & $10 / 13$ & $7 / 16$ & $10 / 10$ & $5 / 5$ & $11 / 9$ & $3 / 5$ & $5 / 9$ \\
\hline \multicolumn{9}{|c|}{ Up-regulated mRNA } \\
\hline$B D K R B 2$ & n.s. & n.s. & n.s. & DOWN & n.s. & n.s. & UP & n.s. \\
\hline CREB5 & n.s. & n.s. & n.s. & n.s. & n.s. & n.s. & UP & UP \\
\hline FGFRL1 & n.s. & - & n.s. & - & - & n.s. & - & n.s. \\
\hline LRRC15 & n.s. & UP & UP & UP & UP & n.s. & n.s. & n.s. \\
\hline SESN3 & UP & - & n.s. & - & - & n.s. & - & n.s. \\
\hline \multicolumn{9}{|c|}{ Down-regulated mRNA } \\
\hline ADAMTS12 & n.s. & n.s. & n.s. & n.s. & - & n.s. & - & DOWN \\
\hline AKAP12 & DOWN & n.s. & DOWN & DOWN & DOWN & n.s. & UP & n.s. \\
\hline COL5A3 & UP & n.s. & n.s. & n.s. & - & n.s. & - & n.s. \\
\hline FAM26E & n.s. & - & n.s. & - & - & n.s. & - & n.s. \\
\hline KCTD20 & n.s. & DOWN & n.s. & n.s. & n.s. & n.s. & DOWN & DOWN \\
\hline KLHL3 & DOWN & n.s. & n.s. & UP & - & n.s. & - & n.s. \\
\hline RGS5 & n.s. & n.s. & DOWN & n.s. & n.s. & n.s. & UP & DOWN \\
\hline SERPINB9 & n.s. & n.s. & n.s. & n.s. & UP & n.s. & n.s. & UP \\
\hline
\end{tabular}

The genes and their directions of expression marked in bold were those that were expressed more consistently in the same directions in RA synovial tissues from GEO datasets. N, normal population; RA, rheumatoid arthritis patients; UP, up-regulated in RA; DOWN, down-regulated in RA; n.s., non-significant between normal and RA; -, no identical probes within the array. 

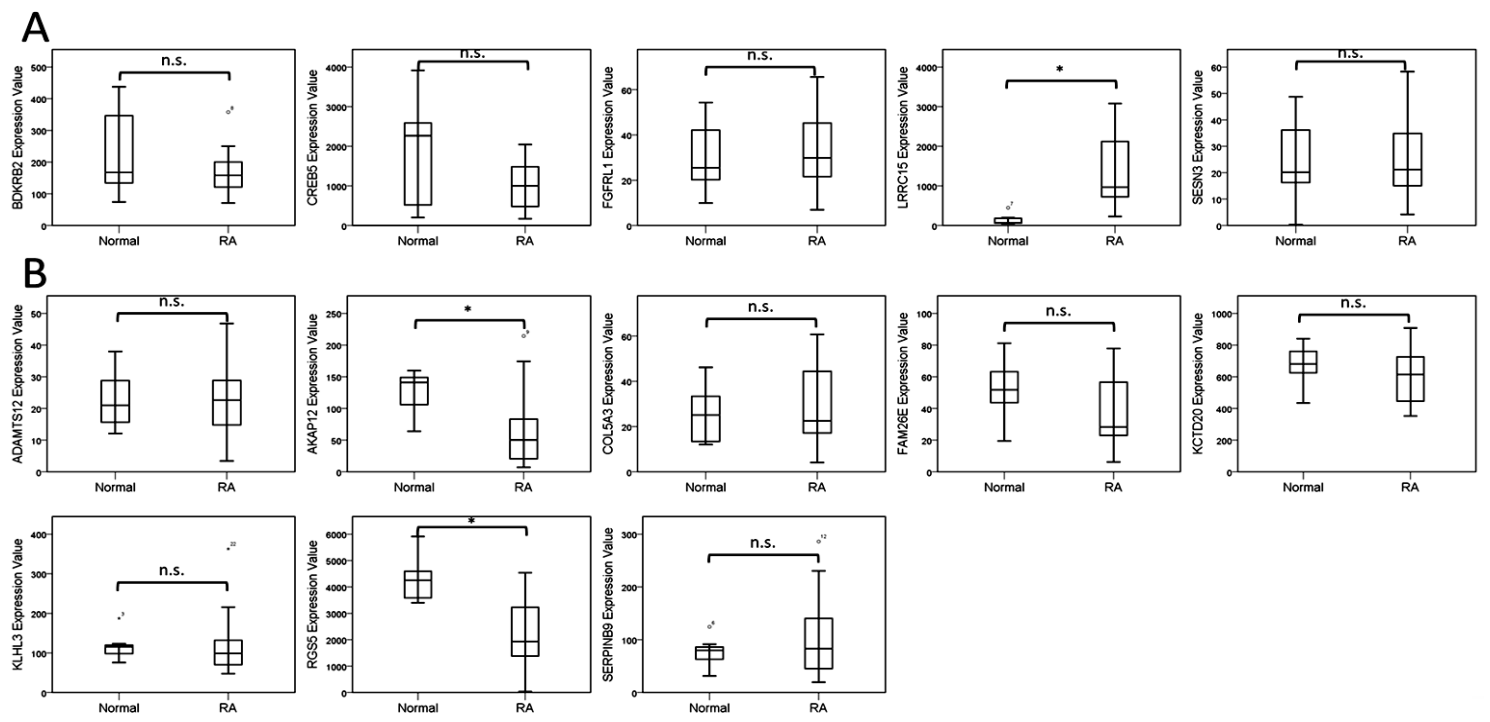

Figure 3. Analysis of 13 genes with potential microRNA-mRNA interactions in the Gene Expression Omnibus (GEO) database. The expression values of: five up-regulated genes (A); and eight down-regulated genes (B) identified from normal and rheumatoid arthritis (RA) osteoblasts were validated in a representative array (GSE77298) of normal and RA synovial tissues from the GEO database. Significant up-regulation of LRRC15 and down-regulation of AKAP12 and RGS5 were observed in the synovial tissues of patients with RA, compared to the normal subjects. * indicated $p<0.05$, and n.s. indicated no statistical significance. (Probe ID reference: BDKRB2, 205870_at; CREB5, 229228_at; FGFRL1, 223321_s_at; LRRC15, 213909_at; SESN3, 242899_at; ADAMTS12, 221421_s_at; $A K A P 12,231067 \_s \_a t ; ~ C O L 5 A 3,218975$ at; FAM26E, 230254_at; KCTD20, 228299_at; KLHL3, 221221_s_at; RGS5, 209071_s_at; and SERPINB9, 242814_at).

\subsection{Potential miRNA-mRNA Interactions of LRRC15 and AKAP12 in RA Osteoblasts}

We used miRmap database to analyze potential miRNA regulations of LRRC15 and AKAP12. Forty-four miRNAs with miRmap score $>99.0$ were potentially involved in the LRRC15 regulation, and 11 miRNAs with miRmap score $>99.0$ were potentially involved in the AKAP12 regulation. Matching to our differentially expressed miRNA database, we identified down-regulated miR-146a-5p that potentially up-regulated $L R R C 15$, and up-regulated miR-183-5p that potentially down-regulated AKAP12, as shown in Table 4. The sequences and putative $3^{\prime} \mathrm{UTR}$ binding sites of representative miRNAs in LRRC15 and AKAP12 were then validated in miRmap, TargetScan and miRDB databases. The target binding sites of miR-146a-5p in the 3'UTR of LRRC15 at the positions of 388-394 and 537-543 were validated in miRmap and TargetScan (Figure 4), while the target binding site of miR-183-5p in the $3^{\prime}$ UTR of AKAP12 at the position of 959-966 was validated in miRmap, TargetScan and miRDB (Figure 5).

Table 4. Potential miRNA regulations of corresponding predicted targets.

\begin{tabular}{cccccc}
\hline $\begin{array}{c}\text { Down-Regulated } \\
\text { miRNA }\end{array}$ & Precursor & Fold-Change & miRmap Score & $\begin{array}{c}\text { Predicted Target } \\
\text { Up-Regulated } \\
\text { mRNA }\end{array}$ & $\begin{array}{c}\text { Fold-Change } \\
\text { (HObRA/HOb) }\end{array}$ \\
\hline hsa-miR-146a-5p & hsa-mir-146a & -2.86 & 99.08 & LRRC15 & 5.85 \\
\hline $\begin{array}{c}\text { Up-Regulated } \\
\text { miRNA }\end{array}$ & Precursor & Fold-Change & miRmap Score & $\begin{array}{c}\text { Predicted Target } \\
\text { Down-Regulated } \\
\text { mRNA }\end{array}$ & $\begin{array}{c}\text { Fold-Change } \\
\text { (HObRA/HOb) }\end{array}$ \\
\hline hsa-miR-183-5p & hsa-mir-183 & 2.29 & 99.56 & $A K A P 12$ & 0.39 \\
\hline
\end{tabular}


A

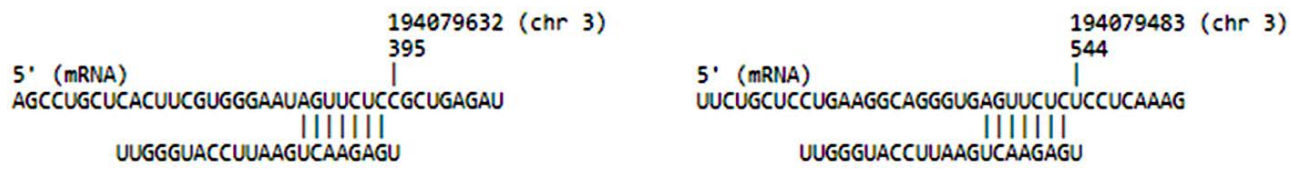

B
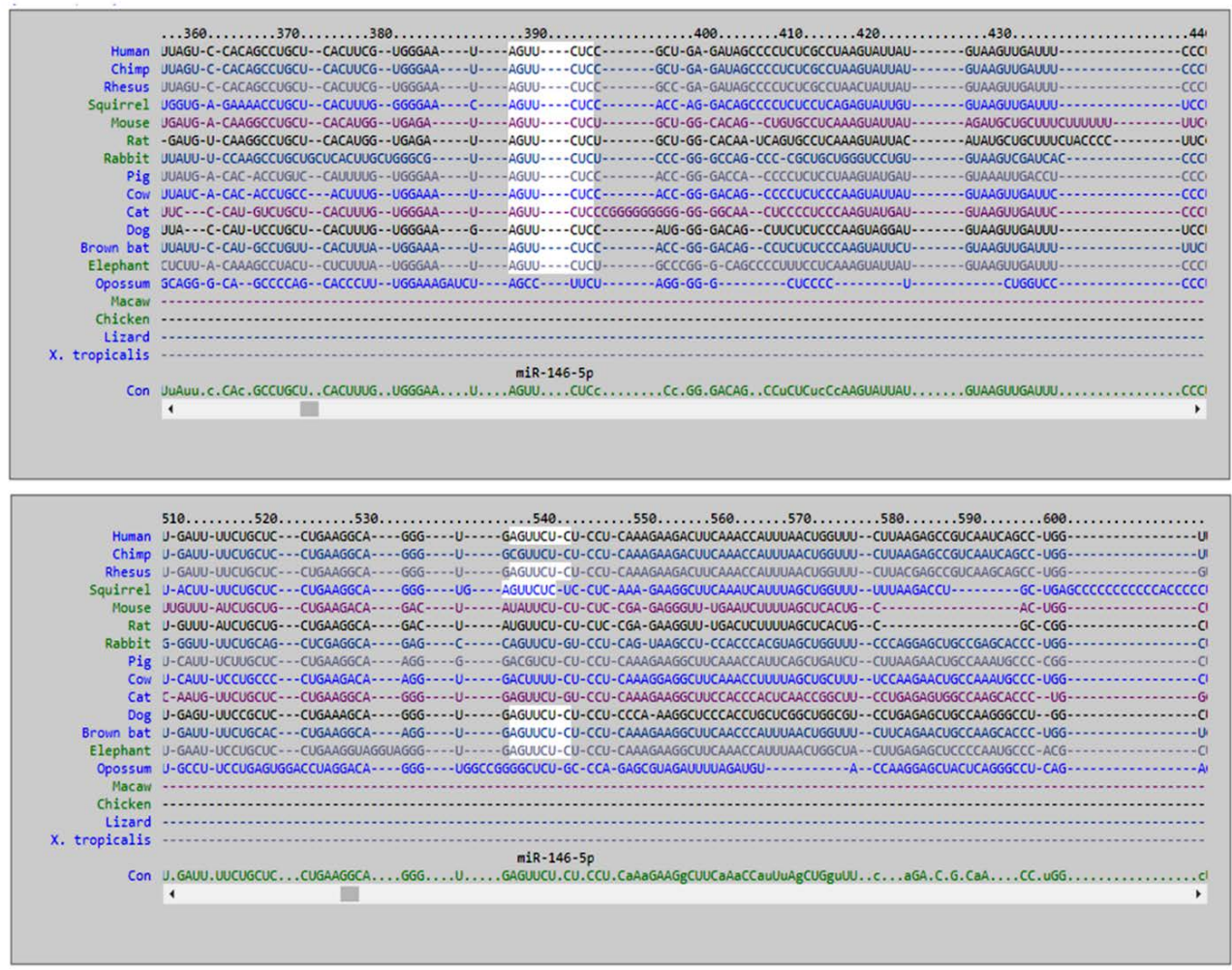

Figure 4. The putative binding sites of miR-146a-5p on $L R R C 15$. The sequences and putative binding sites of miR-146a-5p on the $3^{\prime}$ UTR of LRRC15 at positions of 388-394 and 537-543 were validated in: miRmap (A); and TargetScan (B).

A

5. (mRNA) $151677815(\mathrm{chr} 6)$
UGAUAGAUACUGGAUUGUGUUUGUGCCAUAUUUGUGCC
UCACUUAGGAUGGUCACGGUAU

B

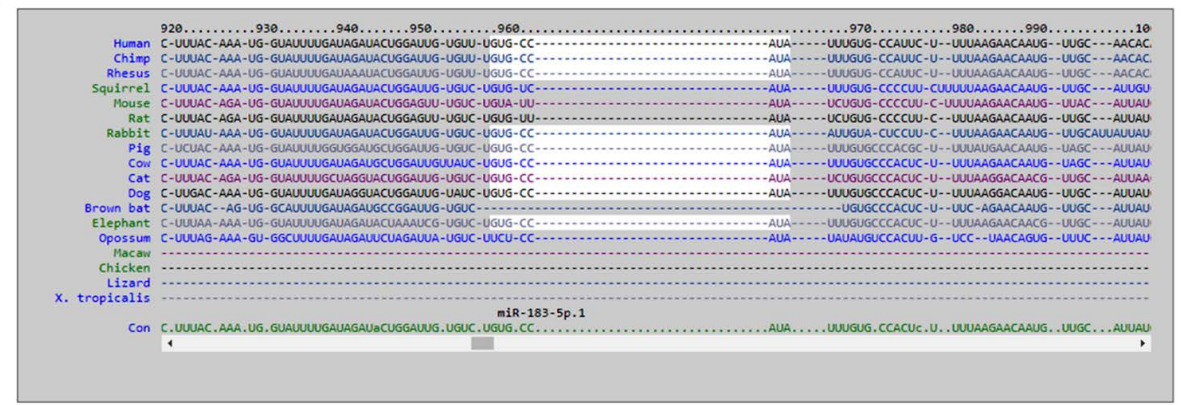

Figure 5. Cont. 


\section{3' utr sequence}

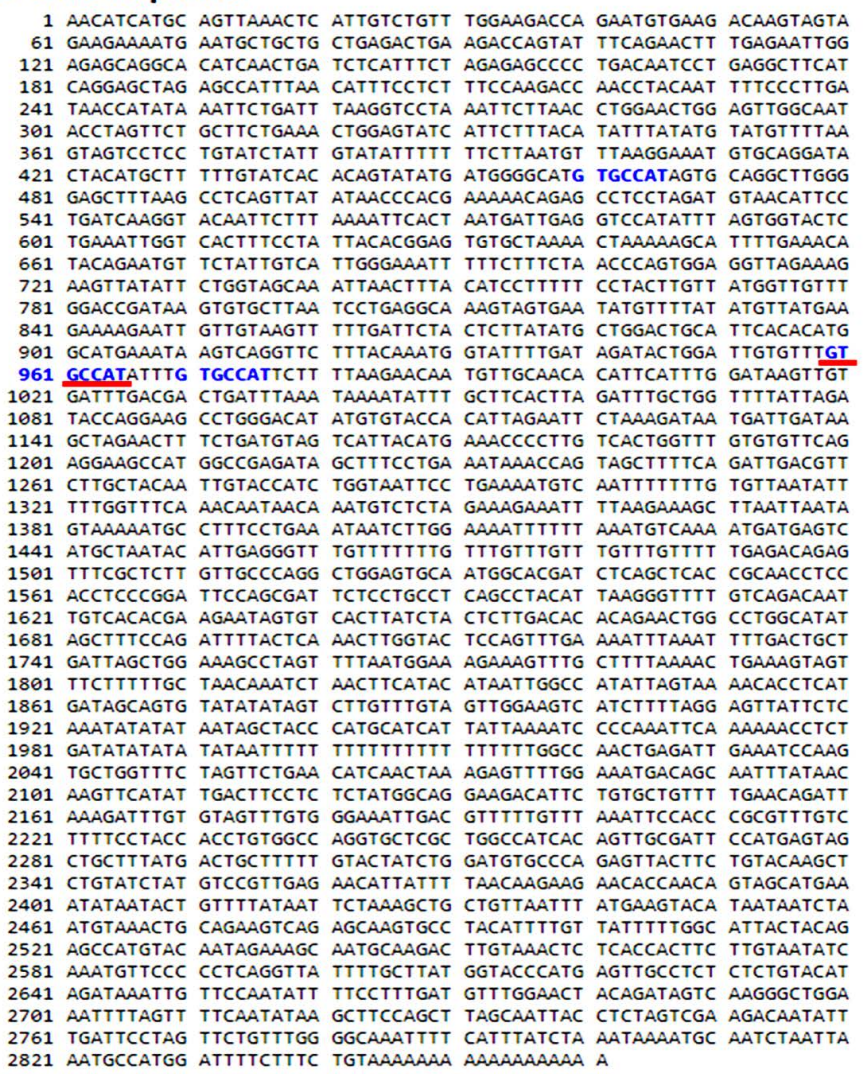

Figure 5. The putative binding site of miR-183-5p on $A K A P 12$. The sequence and putative binding site of miR-183-5p on the 3'UTR of AKAP12 at the position of 959-966 was validated in: miRmap (A); TargetScan (B); and miRDB (C).

Using the IPA software, diseases and functions associated with the 13 candidate genes identified between normal and RA osteoblasts were further analyzed. There were two networks classified, as shown in Table 5, with 10 of the 13 candidate genes involved in network 1 (Figure 6). The previously identified AKAP12 was involved in network 1, while $L R R C 15$ was involved in network 2. One of the miRNAs identified between normal and RA osteoblasts, miR-146a-5p, was also involved in network 1 . Using the overlay diseases and functions tool in the IPA software, we disclosed ADAMTS12, BDKRB1, BDKRB2, BMP1, FGF2, FOXO1, KCTD20, NOTCH4, PPARG, TGFB1 and miR-146a-5p to be associated with "rheumatic disease" and "inflammation of joint" in network 1 , as indicated by purple frames in Figure 6. 
Table 5. Networks associated with 13 candidate genes differentially expressed in RA osteoblasts.

\begin{tabular}{|c|c|c|c|c|}
\hline & $\begin{array}{l}\text { Top Diseases and } \\
\text { Functions }\end{array}$ & Score & $\begin{array}{c}\text { Focus } \\
\text { Molecules }\end{array}$ & Molecules in Network \\
\hline 1. & $\begin{array}{l}\text { Cardiovascular } \\
\text { System } \\
\text { Development and } \\
\text { Function, Cellular } \\
\text { Development, } \\
\text { Cellular Growth } \\
\text { and Proliferation }\end{array}$ & 27 & 10 & $\begin{array}{l}\downarrow \text { ADAMTS12, } \downarrow \text { AKAP12, AKT2, BDKRB1, } \uparrow \text { BDKRB2, } \\
\text { BMP1, COL5A1, } \downarrow \text { COL5A3, collagen, Collagen type I, } \\
\uparrow \text { CREB5, ERK1/2, } \downarrow \text { FAM26E, FGF2, Fgfr, } \uparrow \text { FGFRL1, } \\
\text { FOXO1, GPC1, Hspg2, Kallikrein, } \downarrow \text { KCTD20, KLKB1, } \\
\text { MAPK1, mir-25, mir-181, miR-146a-5p, MIR17HG, } \\
\text { NOTCH2, NOTCH4, plasminogen activator, Plc beta, } \\
\text { PPARG, } \downarrow \text { RGS5, } \uparrow \text { SESN3, TGFB1 }\end{array}$ \\
\hline 2. & $\begin{array}{l}\text { Cellular } \\
\text { Compromise, } \\
\text { Organismal Injury } \\
\text { and Abnormalities, } \\
\text { Hereditary } \\
\text { Disorder }\end{array}$ & 6 & 3 & $\begin{array}{l}\text { AKT2, COASY, DOLPP1, FOSB, FOSL2, FURIN, GBP2, } \\
\text { H2AFB3, IGSF8, JUND, KEAP1, } \downarrow \text { KLHL3, } \uparrow \text { LRRC15, } \\
\text { MAFG, MAPK3, MARK4, miR-3656, miR-423-5p, } \\
\text { miR-4537, miR-6825-5p, MRPS27, NOS3, P2RY8, } \\
\text { PLEKHM1, PRKCG, RAB11B, SELPLG, } \downarrow \text { SERPINB9, } \\
\text { SLC9A1, SMARCD1, TAGLN, UNC119, USF2, WNK2, } \\
\text { WNK4 }\end{array}$ \\
\hline
\end{tabular}

The genes marked in bold were the 13 candidate genes identified in normal and RA osteoblasts.

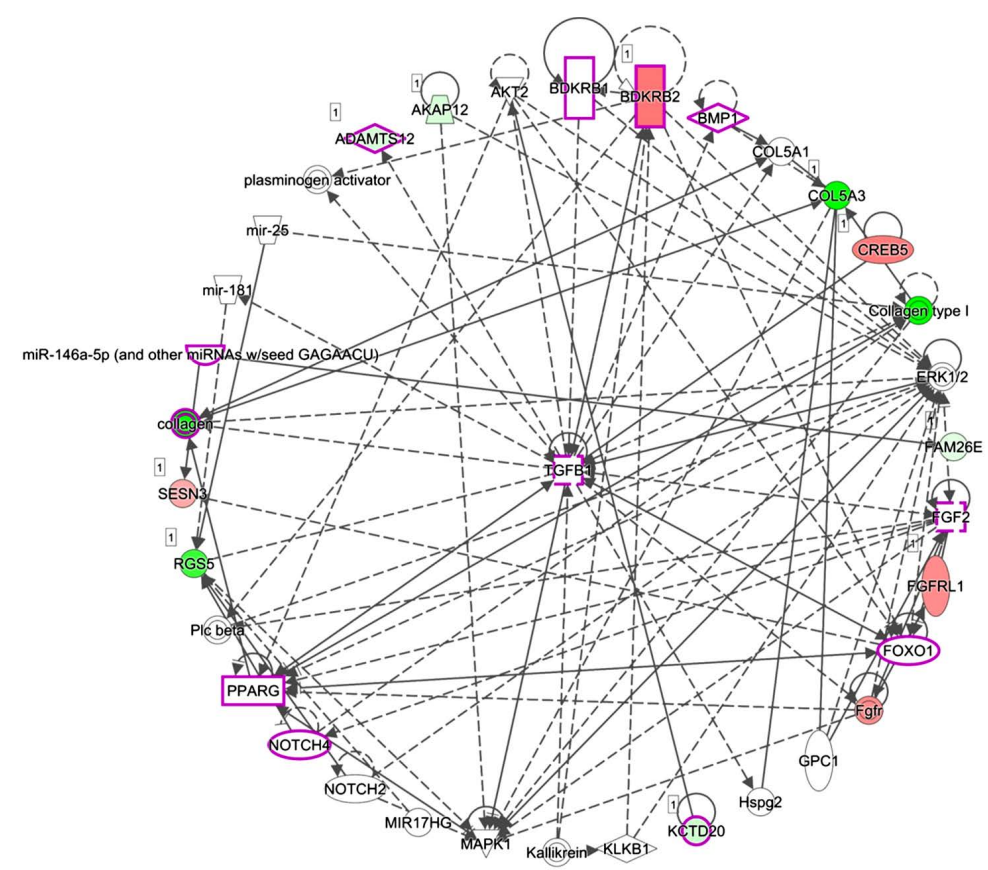

Figure 6. Network analysis by Ingenuity ${ }^{\circledR}$ Pathway Analysis (IPA) indicated molecules associated with rheumatic disease and inflammation of joint. The network analysis was performed by IPA software to indicate networks involved in the 13 candidate genes from rheumatoid arthritis (RA) osteoblasts. Ten of the 13 candidate genes were grouped in one network associated with cardiovascular system development and function, cellular development, cellular growth and proliferation. Molecules including ADAMTS12, BDKRB1, BDKRB2, BMP1, FGF2, FOXO1, KCTD20, NOTCH4, PPARG, TGFB1 and miR-146a-5p were associated with rheumatic disease and inflammation of joint in the network, as indicated in purple frames. Molecules in green indicated down-regulated expressions, and molecules in red indicated up-regulated expressions in RA osteoblasts compared to normal osteoblasts. The green and red color scales disclosed the relative gene expression values of RA to normal osteoblasts.

In addition to network analysis, we found miR-29b-3p to be one of the significant upstream regulators ( $p$-value of overlap $=3.94 \times 10^{-4}$ ), which was 2.51-fold up-regulated in RA osteoblasts compared to normal osteoblasts. The effectors potentially involved in the miR-29b-3p regulation were BDKRB2, COL5A3, CREB5, KCTD20, and SERPINB9 (Table 6). 
Table 6. Upstream regulator miR-29b-3p and potential downstream effectors of RA osteoblasts.

\begin{tabular}{|c|c|c|}
\hline Analysis & Molecules in 13 Candidate Genes & $p$-Value of Overlap \\
\hline $\operatorname{miR}-29 b-3 p$ & $\begin{array}{c}\text { BDKRB2, COL5A3, CREB5, KCTD20, } \\
\text { SERPINB9 }\end{array}$ & $3.94 \times 10^{-4}$ \\
\hline Analysis & $\begin{array}{l}\text { Molecules in } 434 \text { Differentially } \\
\text { Expressed Genes }\end{array}$ & $p$-Value of Overlap \\
\hline $\operatorname{miR}-29 b-3 p$ & $\begin{array}{l}\text { RUNX1T1, PALM, PDPN, LAMA2, } \\
\text { ITGA6, CEMIP, DPP4, HS3ST3B1, } \\
\text { KIF26B, CACNA1A, GPR85, CELF2, } \\
\text { HAPLN1, BDKRB2, NDN, CRYBG1, } \\
\text { CREB5, WISP1, FAM167A, SLC12A8, } \\
\text { COL11A1, DMKN, MEGF6, ENPP2, } \\
\text { ID3, PDGFRB, RTL5, TRAF5, LASP1, } \\
\text { CSPG4, HAPLN3, NEDD9, KCTD20, } \\
\text { SERPINB9, PEG10, UACA, ADAM19, } \\
\text { CTPS1, CCDC85A, FCRLA, TRPC6, } \\
\text { COL5A3, CCDC81, HEYL }\end{array}$ & $1.76 \times 10^{-5}$ \\
\hline
\end{tabular}

2.5. The Differentially Expressed Genes in RA Osteoblasts Were Associated with Chemotaxis, Neovascularization, Cell Adhesion and Extracellular Matrix Organization

To identify pathways and biological functions involved in RA osteoblasts, the 434 differentially expressed protein-coding genes (199 up-regulated genes and 235 down-regulated genes) between normal and RA osteoblasts were further analyzed by the IPA software and the functional annotation tool in the DAVID database. The results of IPA analysis identified TGFB1, TNF, IFNG, and IL1B among the top upstream regulators. miR-29b-3p was also a significant upstream regulator ( $p$-value of overlap $=1.76 \times 10^{-5}$ ), with its effectors listed in Table 6 . The differentially expressed genes were categorized into 25 networks. AKAP12, along with 24 other dysregulated genes were involved in diseases and functions related to cellular development, cellular growth and proliferation, and organ development, whereas 17 dysregulated genes, including $L R R C 15$, were involved in diseases and functions related to hereditary disorder, immunological disease, and organismal injury and abnormalities (Table 7).

Table 7. Two of the networks associated with 434 candidate genes differentially expressed in RA osteoblasts.

\begin{tabular}{|c|c|c|c|}
\hline $\begin{array}{l}\text { Top Diseases and } \\
\text { Functions }\end{array}$ & Score & $\begin{array}{c}\text { Focus } \\
\text { Molecules }\end{array}$ & Molecules in Network \\
\hline $\begin{array}{l}\text { Cellular Development, } \\
\text { Cellular Growth and } \\
\text { Proliferation, Organ } \\
\text { Development }\end{array}$ & 38 & 25 & $\begin{array}{l}\downarrow \text { AKAP12, Cbp } / \text { p300, } \downarrow \text { CDA, } \uparrow \text { CEMIP, } \\
\downarrow \text { CNN1, } \uparrow \text { CRLF1, } \downarrow \text { DOCK10, E2f, EGLN, } \\
\uparrow \text { EPHA4, } \downarrow \text { EPHA5, } \uparrow \text { FGFRL1, } \downarrow \text { FHL1, } \downarrow \text { FLT1, } \\
\text { GTPase, } \downarrow \text { GUCY1B3, Hedgehog, } \downarrow \text { HGF, } \\
\uparrow \text { ICA1, Importin alpha, } \uparrow \text { ITGA6, } \uparrow \text { ITGB8, } \\
\downarrow \text { LMOD1, } \downarrow \text { MYOCD }, \downarrow \text { NOTCH1, } \downarrow \text { PDLIM3, } \\
\uparrow \text { PHLDA1, } \uparrow \text { PLXNA2, Proinsulin, } \downarrow \text { SCUBE3, } \\
\text { Sfk, Smad2/3, } \uparrow \text { SOX9, Vegf, } \uparrow \text { VLDLR }\end{array}$ \\
\hline $\begin{array}{l}\text { Hereditary Disorder, } \\
\text { Immunological Disease, } \\
\text { Organismal Injury and } \\
\text { Abnormalities }\end{array}$ & 22 & 17 & $\begin{array}{l}\uparrow \text { ADM2, ATP6AP1, ATP6V1F, CASP2, } \\
\text { CDK2AP2, } \uparrow \text { CMKLR1, CTSA, } \downarrow \text { CYGB, } \\
\uparrow \text { ELFN1, } \downarrow \text { FAM46B, FOXRED2, GPR84, GRM4, } \\
\downarrow \text { HAAO, } \downarrow \text { HEYL, } \downarrow \text { IRX2, } \downarrow \text { KCTD20, } \uparrow \text { KIF26B, } \\
\text { LDB1, } \uparrow \text { LRRC15, } \downarrow \text { LRRC32, } \downarrow \text { LYPD1, } \\
\text { miR-4656, miR-504-3p, } \uparrow \text { MKX }, \downarrow \text { MX1, PLPPR2, } \\
\downarrow \text { PLPPR4, PPP1CA, RASSF8, } \downarrow \text { SERPINA9, } \\
\text { TBC1D22A, TRIM67, TUFT1, ZNF677 }\end{array}$ \\
\hline
\end{tabular}

The genes marked in bold were the 434 differentially expressed protein-coding genes identified in normal and RA osteoblasts. 
We then determined the interconnection between various diseases and functions, including inflammation of joint, chemotaxis, damage of connective tissue, migration of connective tissue cells, proliferation of osteoblasts, and neovascularization. AKAP12 is one of the genes involved in chemotaxis, having connection with $H G F$ and $A R R B 1$, which are involved in damage of connective tissue and neovascularization. Using the overlay canonical pathway tool in the IPA, molecules involved in protein kinase A signaling, including AKAP12, MAP3K1, VASP, PTK2B, TGFB2, ITPR3, and NFATC1, also take part in the above selected diseases and functions, as indicated by light blue lines in Figure 7.

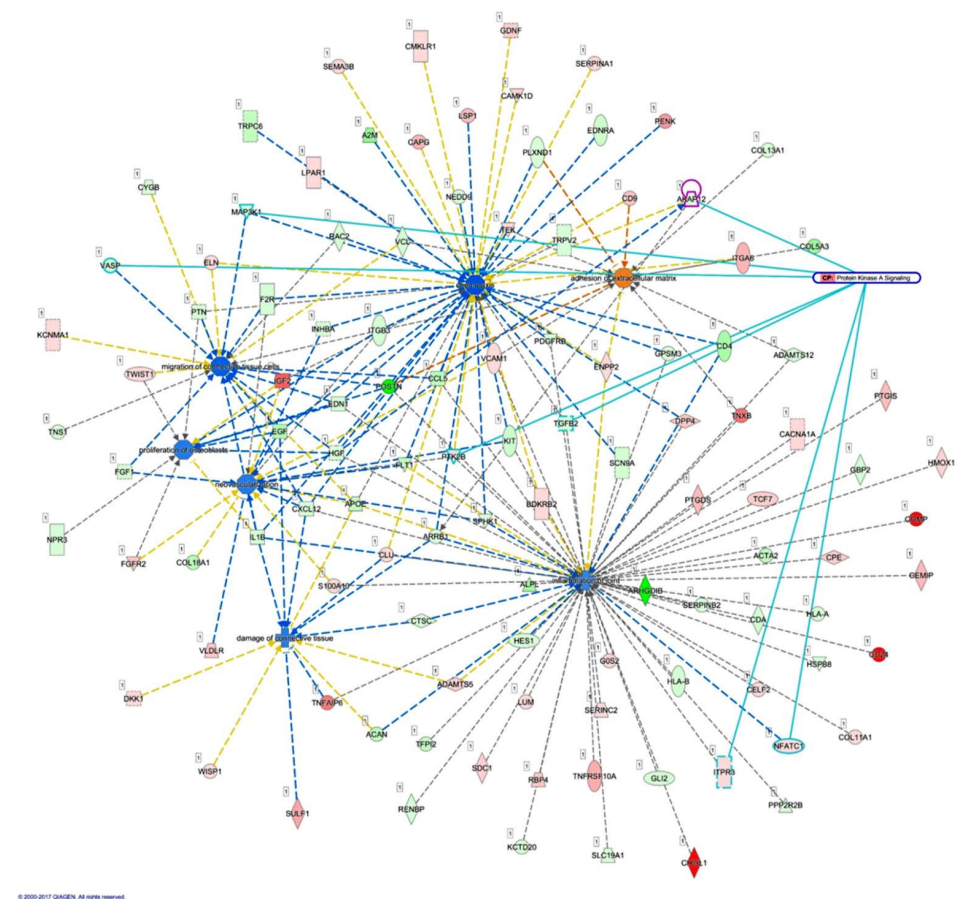

Figure 7. Analysis of the interconnection between AKAP12 and the merged networks of related joint diseases and functions. The 434 differentially expressed genes identified in normal and rheumatoid arthritis (RA) osteoblasts were analyzed by the IPA to be categorized into 25 networks. Diseases and functions related to joint destruction in RA microenvironment, including inflammation of joint, chemotaxis, damage of connective tissue, migration of connective tissue cells, proliferation of osteoblasts, and neovascularization were selected to identify related genes. AKAP12, one of the genes involved in chemotaxis, was connected to HGF and ARRB1, molecules involved in damage of connective tissue and neovascularization. In addition, the overlay canonical pathway analysis indicated AKAP12, MAP3K1, VASP , PTK2B, TGFB2, ITPR3, and NFATC1 (marked in light blue) to be involved in the protein kinase A signaling, and participated in various indicated networks.

Using the DAVID database for the analysis of biological functions, the top 10 biological functions involved in these differentially expressed genes of RA osteoblasts were cell adhesion (38 genes), extracellular matrix organization ( 23 genes), positive regulation of cell migration ( 21 genes), skeletal system development (18 genes), angiogenesis (22 genes), type I interferon signaling pathway (12 genes), positive regulation of cell proliferation (31 genes), response to hypoxia (18 genes), heart development (18 genes), and positive regulation of PI3K signaling (11 genes), as shown in Figure 8. 


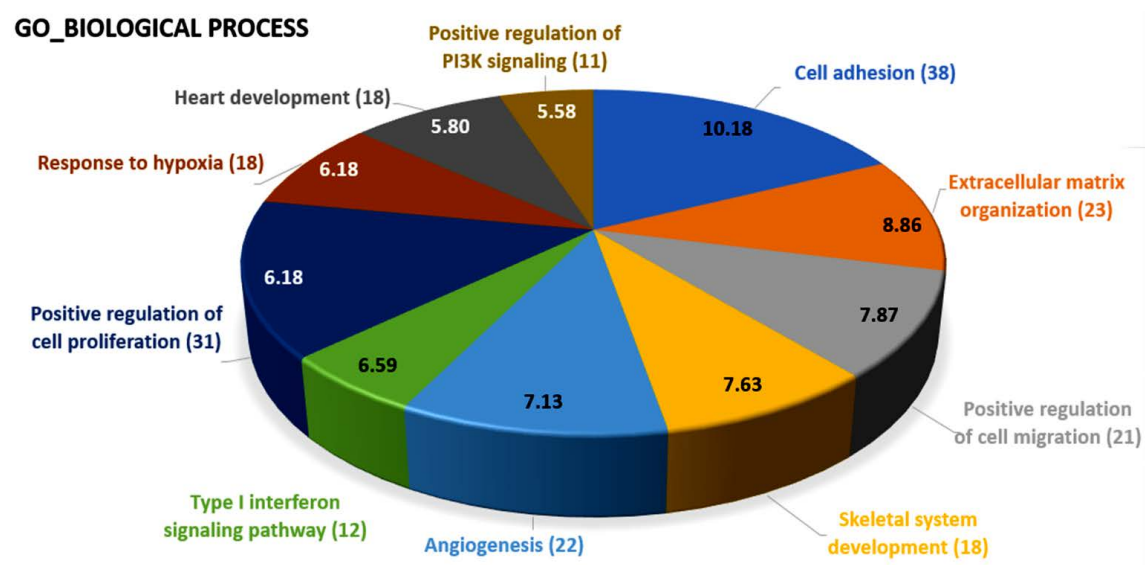

Figure 8. The biological process analysis of differentially expressed genes in rheumatoid arthritis osteoblasts. The 434 differentially expressed genes in rheumatoid arthritis osteoblasts were analyzed in the DAVID database for the identification of involved biological processes. The results indicated these genes were potentially involved in cell adhesion (38 genes), extracellular matrix organization (23 genes), positive regulation of cell migration (21 genes), skeletal system development (18 genes), angiogenesis (22 genes), type I interferon signaling pathway (12 genes), positive regulation of cell proliferation (31 genes), response to hypoxia (18 genes), heart development (18 genes), and positive regulation of PI3K signaling (11 genes). The selected criteria for functional annotation analysis were $\mathrm{EASE}=0.1$ and fold enrichment $>1.3$. The proportions of the pie chart were drawn according to the numbers of genes involved in each biological term, and the numbers within the pie chart indicated $-\log (p$-value) of each biological term.

\section{Discussion}

The current study identified 35 differentially expressed miRNAs and 13 candidate genes potentially involved in osteoblasts of RA, using NGS and bioinformatics analysis. Two of the 13 candidate genes differentially expressed in osteoblasts of RA, LRRC15 and AKAP12, were found to have consistent direction of expression in the synovial tissue of RA patients identified in four of the five RA array datasets (GSE7307, GSE55475, GSE77298, GSE55235, and GSE1919). The potential miRNA regulation on LRRC15 was miR-146a-5p, whereas the potential miRNA regulation on AKAP12 was miR-183-5p, predicted by miRmap, TargetScan and miRDB database. We proposed the novel findings of miR-146a-5p-LRRC15 and miR-183-5p-AKAP12 regulations in the altered function of osteoblasts in RA microenvironment.

The role of osteoblasts in the development of bone loss and limited capacity of repair of bone erosion in RA has received more attention recently, and miRNAs are hypothesized to play critical roles in the regulation of the function of osteoblasts in RA $[13,15,28]$. The results of IPA analysis identified miR-29b-3p to be a potential upstream regulator of the differentially expressed genes in RA. The regulation of the miR-29 family is proposed to participate in osteoarthritis and cartilage homeostasis [29]. In addition, the miR-29 family has been shown to promote osteoblast differentiation by targeting inhibitors of the Wnt signaling pathway, and to possess numerous distinct activities at different stages of osteoblast differentiation. In the mature osteoblasts, miR-29 targets collagen type I, reducing the rate of collagen synthesis and facilitating structural stability of the bone [30]. In a review article by Miao et al., the Wnt signaling pathway participates in the pathogenesis of RA and bone remodeling. They suggested that inhibition of the Wnt signaling pathway may contribute to impaired osteoblast function in RA, and increased expression of several inhibitors of the Wnt signaling pathway may contribute to bone resorption in RA [31]. Two of the effectors of miR-29b-3p in our candidate genes, BDKRB2 and SERPINB9, were categorized into the molecular function of protease binding by gene ontology, as shown in Figure 2A and Table 6, which may support the involvement of miR-29b-3p in the regulation of bone matrix in RA. 
A-kinase anchoring protein 12 (AKAP12), one of the A-kinase anchoring proteins, is a scaffold protein for protein kinase A (PKA) and protein kinase C (PKC) that control cytoskeleton dynamics, cell migration, and cell adhesion [32,33]. Studies suggested that the down-regulation of AKAP12 induces the formation of stress fibers and proliferation of adhesion complexes; increased cellular senescence was also observed in AKAP12-null mice [34]. The findings potentially link AKAP12 to the disrupted bone homeostasis in RA, where the study by Yudoh and colleagues revealed the higher rate of cellular senescence and greater decline in the replicative capacity of peri-articular osteoblasts in RA patients, compared to osteoarthritic patients [15]. The expressions of AKAP12 in inflammatory responses were studied. The increased protein expression of AKAP12 in the fibrotic scar may restrict excessive inflammation during central nervous system repair [35], and decreased protein levels of AKAP12 were observed in the lung tissue of patients with chronic obstructive pulmonary disease [36], suggesting the participation of AKAP12 in the regulation of inflammatory response. There is not much literature discussing the role of AKAP12 in the bone homeostasis or the inflamed joint microenvironment. One study identified Akap12 to be one of the genes possibly involved in the alternative splicing in bone following mechanical loading in rat model [37]. The altered joint structures along with inflamed peri-articular soft tissue in RA predispose the affected joint to increased mechanical loading, which may disrupt the PKA-mediated mechanotransduction.

Scaffold proteins serve as connecting hubs that modulate both upstream signaling molecules and the downstream effectors within cells. The expression and activity of AKAP12 is proposed to be affected by the hypoxic tumor microenvironment [38]. Studies also suggested AKAP12 to be a tumor suppressor and angiogenesis suppressor gene that down-regulates vascular endothelial growth factor, potentially through epigenetic regulation [39]. The role of miRNA regulation in altered bone homeostasis has been reported $[20,21]$. Few studies also reported that miR-183 increased osteoclastogenesis through the binding on the $3^{\prime}$ UTR of heme oxygenase-1 [40], and oxidative stress within the bone marrow microenvironment may alter miRNA cargo of extracellular vesicles, expressing high abundance of miR-183 cluster and miR-183-5p transfection inhibits the osteogenic differentiation of bone marrow stromal cells [41]. Altogether, with these literature reviews, the up-regulated miR-183-5p with its putative target of down-regulated $A K A P 12$ in our NGS result suggests the novel finding of potential miR-183-5p-AKAP12 regulation in the changed bone homeostasis in RA joint microenvironment.

Leucine rich repeat containing 15 ( $L R R C 15$ ), also named $L I B$, is a gene encoding leucine-rich transmembrane protein that participates in the cell-matrix adhesion and cell migration, and is induced and highly expressed in various cancer types [42-44]. The role of LRRC15 in inflammation is also proposed, as it is induced by beta-amyloid and pro-inflammatory cytokines in astrocytes of Alzheimer's disease brain $[45,46]$ and up-regulated by pro-inflammatory stimuli during the process of dental caries [47]. There is still lack of related literature on the role of LRRC15 in the arthritic joint microenvironment or other bone diseases.

miR-146a-5p was identified to be one of the molecules associated with the inflammation of joint in the IPA analysis, as indicated in Figure 6. miR-146 is one of the miRNAs strongly implicated in $\mathrm{RA}$, regulating a group of target genes related to inflammation. The level of miR-146a is increased in synovial tissue, synovial fluid, whole blood and many other cells types such as T cells, B cells and macrophages. However, the association between the expression level of miR-146a and disease activity is still inconclusive [48]. miR-146a is also proposed to prevent joint destruction in arthritic mice by inhibiting osteoclastogenesis [49]. Our results indicated the potential regulation of miR-146a-5p on LRRC15. Whether the regulation of miR-146a-5p in bone is mediated by inflammatory joint microenvironment or other stimuli merits further clarification.

The interconnection between different cell types and the arthritic microenvironment is complex yet important in the understanding of the RA disease entity. The area of pannus formation is infiltrated by synoviocytes, immune cells, osteoclasts and proliferative vessels, and comes into direct contact with adjacent bone surface, where osteoblasts reside [9]. Along with immune cells and synovial fibroblasts, the role of osteoblasts in the pathogenesis of articular destruction in RA have gained much attention, 
with the function of osteoblasts being compromised at sites of focal erosion and reduced mineralization of the newly formed bone in the arthritic joints [50]. The activity and function of osteoblasts is also inhibited by the hypoxia within the arthritic joint microenvironment [51]. In the current study, we explored novel miRNAs and the putative targets expressed in the osteoblasts of RA origin. Several of the target genes identified in our study were also found to have consistent directions of expression in the synovial tissues of RA patients from related GEO array datasets. The schematic potential molecular mechanisms are summarized in Figure 9. These identified miRNA-mRNA regulations may provide novel perspectives into deeper understanding of the cell-cell communication between different cell types within the joint structure and the role of arthritic joint microenvironment in the altered bone homeostasis.

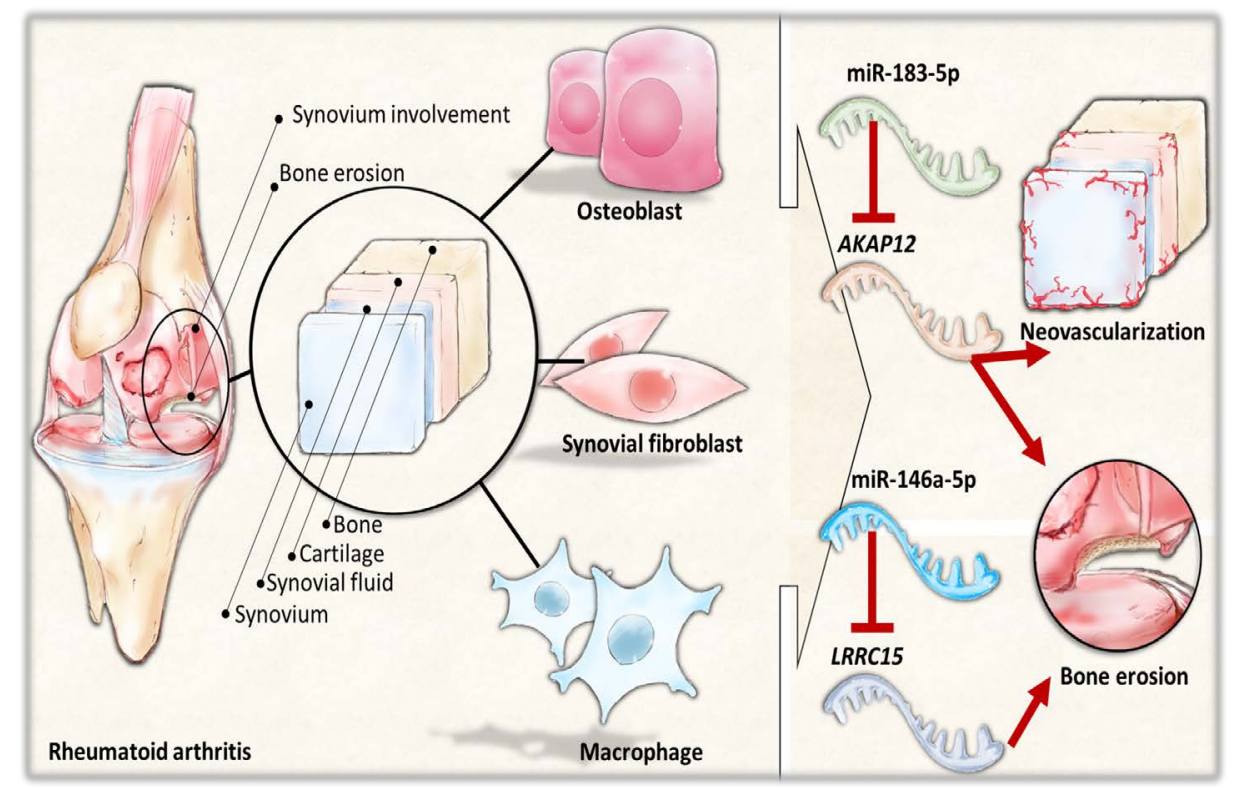

Figure 9. The proposed novel molecular signatures and microRNA regulations in rheumatoid arthritis osteoblasts.

\section{Materials and Methods}

\subsection{Primary Cell Culture}

Osteoblasts isolated from normal human bones (HOb, Catalog No. 406-05a, Lot No. 3145) and bones of patients with RA (HObRA, Catalog No. 406RA-05a, Lot No. 1796) were purchased from Cell Applications, Inc. (San Diego, CA, USA). In detail, osteoblasts of normal bone were obtained from a 66-year-old female, and osteoblasts of RA bone were obtained from a 72-year-old female with RA. Osteoblasts were grown in human osteoblast growth medium (Cell Applications, Inc.) and maintained in $37{ }^{\circ} \mathrm{C}$ incubator containing $5 \% \mathrm{CO}_{2}$ until confluence. The $\mathrm{HOb}$ and $\mathrm{HObRA}$ cells were then harvested for total RNA extraction and further mRNA and small RNA profiling.

\subsection{RNA Sequencing}

To prepare samples for mRNA and small RNA profiling, total RNAs from HOb and HObRA cells were extracted by Trizol ${ }^{\circledR}$ Reagent (Invitrogen, Carlsbad, CA, USA) according to the manufacturer's instructions. Before further sequencing, the quality of extracted RNAs were analyzed by $\mathrm{OD}_{260}$ detection using ND-1000 spectrophotometer (Nanodrop Technology, Wilmington, DE, USA) and validated by RNA integrity number (RIN) with Agilent Bioanalyzer (Agilent Technology, Santa Clara, CA, USA), where RINs for HOb and HObRA were 9.9 and 10, respectively. Total RNA sequencing analysis for RNA-seq and small RNA-seq were performed by Welgene Biotechnology Company 
(Welgene, Taipei, Taiwan). We set the criteria for differentially expressed mRNAs and miRNAs at fold change $>2.0$, FPKM $>0.3$ for mRNA and RPM $>10$ for miRNA.

\section{3. miRmap Database}

miRmap is an open-source database that provides miRNA target prediction using a comprehensive approach with various computational tools, including thermodynamic, evolutionary, probabilistic and sequence-based approaches. The repression strength of a miRNA-mRNA interaction of interest is indicated by the miRmap score. The higher miRmap score indicates higher repression strength. The 35 differentially expressed miRNAs were consecutively inputted to obtain putative target genes, and those with miRmap scores higher than 99.0 were selected for further analysis [24].

\subsection{Gene Expression Omnibus (GEO)}

The GEO database provides public access to high-throughput array- and sequence-based data. The dataset of interest also provides link to web-based tool such as GEO2R and users can look for candidate genes and perform further analysis by obtaining raw data with expression values of specific genes in the array [25]. The arrays related to joint tissues of RA patients (GSE1919, GSE55235, GSE55475, GSE7307, GSE77298, GSE29746, GSE10500 and GSE7779) were used in this study to identify genes that expressed in consistent directions with our NGS results.

\subsection{Ingenuity ${ }^{\circledR}$ Pathway Analysis (IPA)}

The Ingenuity ${ }^{\circledR}$ Pathway Analysis (IPA) software (Ingenuity systems, Redwood City, CA, USA) contains large database with detailed and structured findings reviewed by experts which was derived from thousands of biological, chemical and medical researches, and provide researchers with quick searching. The IPA also enables analysis, integration, and recognition of data from gene and SNP arrays, RNA and small RNA sequencing, proteomics and many other biological experiments; in addition, deeper understanding and identification of related signaling pathways, upstream regulators, molecular interactions, disease process and candidate biomarkers are also available [26].

\subsection{DAVID Database}

The DAVID database is a bioinformatics resource that assists in the analysis of a list of genes derived from high-throughput genomic sequencing experiments, using different tools such as functional annotation and gene functional classification. The analysis results help researchers gain overall understanding of the involved terms of gene ontology, signaling pathways and diseases within the genes of interest [27].

\subsection{Statistical Analysis}

The expression values of target genes obtained from arrays of GEO database were analyzed using IBM SPSS Statistics for Windows, version 19 (IBM Corp., Armonk, NY, USA). To compare the differences of expression values between normal and RA groups, non-parametric method with Mann-Whitney U test was used. A statistically significant difference was determined by $p$-value $<0.05$.

\section{Conclusions}

Our study indicates that miR-183-5p-AKAP12 and miR-146a-5p-LRRC15 regulations participate in the altered function of osteoblasts in RA joint microenvironment, which are partly responsible for the pathogenesis of bone erosions. The current findings suggest new candidate genes as potential indicators in evaluating therapies targeting chemotaxis and neovascularization to control joint destruction in RA.

Acknowledgments: The authors gratefully acknowledge the support of research grants from the Ministry of Science and Technology (MOST 104-2320-B-037-014-MY3 and MOST-105-2314-B-037-012), Kaohsiung Medical University Aim for the Top Universities Grants (KMU-TP104B10 and KMU-TP105B11), Kaohsiung Medical 
University Hospital (KMUHS10601, KMUH105-5R66, KMUH104-4K35, and KMUH104-4M54), Kaohsiung Municipal Ta-Tung Hospital (kmtth-102-009), and the "KMU-KMUH Co-Project of Key Research" (Grant No. KMU-DK 107009) from Kaohsiung Medical University).

Author Contributions: Po-Lin Kuo, Chia-Hsin Chen, and Ya-Ling Hsu conceived and designed the experiments; Yi-Jen Chen and Wei-An Chang performed the experiments; Yi-Jen Chen, Wei-An Chang, Chia-Hsin Chen, and Po-Lin Kuo analyzed the data; Yi-Jen Chen wrote the manuscript; and all authors contributed to the editing and final approval of the manuscript.

Conflicts of Interest: The authors declare no conflict of interest.

\section{Abbreviations}

$\begin{array}{ll}\text { AKAP12 } & \text { A-Kinase Anchoring Protein } 12 \\ \text { DAVID } & \text { Database for Annotation, Visualization and Integrated Discovery } \\ \text { FPKM } & \text { Fragments per Kilobase of Transcript per Million } \\ \text { GEO } & \text { Gene Expression Omnibus } \\ \text { HOb } & \text { Osteoblasts Isolated from Normal Human Bones } \\ \text { HObRA } & \text { Osteoblasts Isolated from Rheumatoid Arthritis Bones } \\ \text { IPA } & \text { Ingenuity }{ }^{\circledR} \text { Pathway Analysis } \\ \text { LRRC15 } & \text { Leucine Rich Repeat Containing } 15 \\ \text { miRNAs } & \text { microRNAs } \\ \text { NGS } & \text { Next Generation Sequencing } \\ \text { PKA } & \text { Protein Kinase A } \\ \text { RA } & \text { Rheumatoid Arthritis } \\ \text { RANKL } & \text { Receptor Activator of Nuclear Factor } \kappa B \text { Ligand } \\ \text { RPM } & \text { Reads per Million }\end{array}$

\section{References}

1. Scott, D.L.; Wolfe, F.; Huizinga, T.W. Rheumatoid arthritis. Lancet 2010, 376, 1094-1108. [CrossRef]

2. Grassi, W.; De Angelis, R.; Lamanna, G.; Cervini, C. The clinical features of rheumatoid arthritis. Eur. J. Radiol. 1998, 27 (Suppl. 1), S18-S24. [CrossRef]

3. Choy, E. Understanding the dynamics: Pathways involved in the pathogenesis of rheumatoid arthritis. Rheumatology 2012, 51 (Suppl. 5), v3-v11. [CrossRef] [PubMed]

4. Otero, M.; Goldring, M.B. Cells of the synovium in rheumatoid arthritis. Chondrocytes. Arthritis Res. Ther. 2007, 9, 220. [CrossRef] [PubMed]

5. Lipsky, P.E. Why does rheumatoid arthritis involve the joints? N. Engl. J. Med. 2007, 356, $2419-2420$. [CrossRef] [PubMed]

6. Pap, T.; Meinecke, I.; Muller-Ladner, U.; Gay, S. Are fibroblasts involved in joint destruction? Ann. Rheum. Dis. 2005, 64 (Suppl. 4), iv52-iv54. [CrossRef] [PubMed]

7. Lories, R. The balance of tissue repair and remodeling in chronic arthritis. Nat. Rev. Rheumatol. 2011, 7, 700-777. [CrossRef] [PubMed]

8. Schett, G.; Gravallese, E. Bone erosion in rheumatoid arthritis: Mechanisms, diagnosis and treatment. Nat. Rev. Rheumatol. 2012, 8, 656-664. [CrossRef] [PubMed]

9. Jung, S.M.; Kim, K.W.; Yang, C.W.; Park, S.H.; Ju, J.H. Cytokine-mediated bone destruction in rheumatoid arthritis. J. Immunol. Res. 2014, 2014, 263625. [CrossRef] [PubMed]

10. Elshabrawy, H.A.; Chen, Z.; Volin, M.V.; Ravella, S.; Virupannavar, S.; Shahrara, S. The pathogenic role of angiogenesis in rheumatoid arthritis. Angiogenesis 2015, 18, 433-448. [CrossRef] [PubMed]

11. Biniecka, M.; Connolly, M.; Gao, W.; Ng, C.T.; Balogh, E.; Gogarty, M.; Santos, L.; Murphy, E.; Brayden, D.; Veale, D.J.; et al. Redox-mediated angiogenesis in the hypoxic joint of inflammatory arthritis. Arthritis Rheumatol. 2014, 66, 3300-3310. [CrossRef] [PubMed]

12. Alves, C.H.; Farrell, E.; Vis, M.; Colin, E.M.; Lubberts, E. Animal models of bone loss in inflammatory arthritis: From cytokines in the bench to novel treatments for bone loss in the bedside-A comprehensive review. Clin. Rev. Allergy Immunol. 2016, 51, 27-47. [CrossRef] [PubMed] 
13. Walsh, N.C.; Reinwald, S.; Manning, C.A.; Condon, K.W.; Iwata, K.; Burr, D.B.; Gravallese, E.M. Osteoblast function is compromised at sites of focal bone erosion in inflammatory arthritis. J. Bone Miner. Res. 2009, 24, 1572-1585. [CrossRef] [PubMed]

14. Abbas, S.; Zhang, Y.H.; Clohisy, J.C.; Abu-Amer, Y. Tumor necrosis factor-alpha inhibits pre-osteoblast differentiation through its type-1 receptor. Cytokine 2003, 22, 33-41. [CrossRef]

15. Yudoh, K.; Matsuno, H.; Osada, R.; Nakazawa, F.; Katayama, R.; Kimura, T. Decreased cellular activity and replicative capacity of osteoblastic cells isolated from the periarticular bone of rheumatoid arthritis patients compared with osteoarthritis patients. Arthritis Rheum. 2000, 43, 2178-2188. [CrossRef]

16. Jones, D.; Glimcher, L.H.; Aliprantis, A.O. Osteoimmunology at the nexus of arthritis, osteoporosis, cancer, and infection. J. Clin. Investig. 2011, 121, 2534-2542. [CrossRef] [PubMed]

17. Takayanagi, H. Osteoimmunology: Shared mechanisms and crosstalk between the immune and bone systems. Nat. Rev. Immunol. 2007, 7, 292-304. [CrossRef] [PubMed]

18. Tran, N.; Hutvagner, G. Biogenesis and the regulation of the maturation of miRNAs. Essays Biochem. 2013, 54, 17-28. [CrossRef] [PubMed]

19. Krol, J.; Loedige, I.; Filipowicz, W. The widespread regulation of microRNA biogenesis, function and decay. Nat. Rev. Genet. 2010, 11, 597-610. [CrossRef] [PubMed]

20. Pi, C.; Li, Y.P.; Zhou, X.; Gao, B. The expression and function of microRNAs in bone homeostasis. Front. Biosci. 2015, 20, 119-138.

21. Moore, B.T.; Xiao, P. MiRNAs in bone diseases. Microrna 2013, 2, 20-31. [CrossRef] [PubMed]

22. Zhao, M.; Liu, D.; Qu, H. Systematic review of next-generation sequencing simulators: Computational tools, features and perspectives. Brief Funct. Genomics 2017, 16, 121-128. [CrossRef] [PubMed]

23. Hao, R.; Du, H.; Guo, L.; Tian, F.; An, N.; Yang, T.; Wang, C.; Wang, B.; Zhou, Z. Identification of dysregulated genes in rheumatoid arthritis based on bioinformatics analysis. PeerJ 2017, 5, e3078. [CrossRef] [PubMed]

24. Vejnar, C.E.; Zdobnov, E.M. MiRmap: Comprehensive prediction of microRNA target repression strength. Nucleic Acids Res. 2012, 40, 11673-11683. [CrossRef] [PubMed]

25. Clough, E.; Barrett, T. The Gene Expression Omnibus Database. Methods Mol. Biol. 2016, 1418, $93-110$. [CrossRef] [PubMed]

26. Thomas, S.; Bonchev, D. A survey of current software for network analysis in molecular biology. Hum. Genomics 2010, 4, 353-360. [CrossRef] [PubMed]

27. Huang da, W.; Sherman, B.T.; Lempicki, R.A. Systematic and integrative analysis of large gene lists using DAVID bioinformatics resources. Nat. Protoc. 2009, 4, 44-57. [CrossRef] [PubMed]

28. Baum, R.; Gravallese, E.M. Bone as a Target Organ in Rheumatic Disease: Impact on Osteoclasts and Osteoblasts. Clin. Rev. Allergy Immunol. 2016, 51, 1-15. [CrossRef] [PubMed]

29. Le, L.T.; Swingler, T.E.; Crowe, N.; Vincent, T.L.; Barter, M.J.; Donell, S.T.; Delany, A.M.; Dalmay, T.; Young, D.A.; Clark, I.M. The microRNA-29 family in cartilage homeostasis and osteoarthritis. J. Mol. Med. 2016, 94, 583-596. [CrossRef] [PubMed]

30. Lian, J.B.; Stein, G.S.; van Wijnen, A.J.; Stein, J.L.; Hassan, M.Q.; Gaur, T.; Zhang, Y. MicroRNA control of bone formation and homeostasis. Nat. Rev. Endocrinol. 2012, 8, 212-227. [CrossRef] [PubMed]

31. Miao, C.G.; Yang, Y.Y.; He, X.; Li, X.F.; Huang, C.; Huang, Y.; Zhang, L.; Lv, X.W.; Jin, Y.; Li, J. Wnt signaling pathway in rheumatoid arthritis, with special emphasis on the different roles in synovial inflammation and bone remodeling. Cell Signal 2013, 25, 2069-2078. [CrossRef] [PubMed]

32. Su, B.; Bu, Y.; Engelberg, D.; Gelman, I.H. SSeCKS/Gravin/AKAP12 inhibits cancer cell invasiveness and chemotaxis by suppressing a protein kinase C-Raf/MEK/ERK pathway. J. Biol. Chem. 2010, 285, 4578-4586. [CrossRef] [PubMed]

33. Wong, W.; Scott, J.D. AKAP signalling complexes: Focal points in space and time. Nat. Rev. Mol. Cell Biol. 2004, 5, 959-970. [CrossRef] [PubMed]

34. Akakura, S.; Gelman, I.H. Pivotal role of AKAP12 in the regulation of cellular adhesion dynamics: Control of cytoskeletal architecture, cell migration, and mitogenic signaling. J. Signal Transduct. 2012, 2012, 529179. [CrossRef] [PubMed]

35. Cha, J.H.; Wee, H.J.; Seo, J.H.; Ahn, B.J.; Park, J.H.; Yang, J.M.; Lee, S.W.; Kim, E.H.; Lee, O.H.; Heo, J.H.; et al. AKAP12 mediates barrier functions of fibrotic scars during CNS repair. PLoS ONE 2014, 9, e94695. [CrossRef] [PubMed] 
36. Poppinga, W.J.; Heijink, I.H.; Holtzer, L.J.; Skroblin, P.; Klussmann, E.; Halayko, A.J.; Timens, W.; Maarsingh, H.; Schmidt, M. A-kinase-anchoring proteins coordinate inflammatory responses to cigarette smoke in airway smooth muscle. Am. J. Physiol. Lung Cell. Mol. Physiol. 2015, 308, L766-L775. [CrossRef] [PubMed]

37. Mantila Roosa, S.M.; Liu, Y.; Turner, C.H. Alternative splicing in bone following mechanical loading. Bone 2011, 48, 543-551. [CrossRef] [PubMed]

38. Finger, E.C.; Castellini, L.; Rankin, E.B.; Vilalta, M.; Krieg, A.J.; Jiang, D.; Banh, A.; Zundel, W.; Powell, M.B.; Giaccia, A.J. Hypoxic induction of AKAP12 variant 2 shifts PKA-mediated protein phosphorylation to enhance migration and metastasis of melanoma cells. Proc. Natl. Acad. Sci. USA 2015, 112, 4441-4446. [CrossRef] [PubMed]

39. Turtoi, A.; Mottet, D.; Matheus, N.; Dumont, B.; Peixoto, P.; Hennequiere, V.; Deroanne, C.; Colige, A.; De Pauw, E.; Bellahcene, A.; et al. The angiogenesis suppressor gene AKAP12 is under the epigenetic control of HDAC7 in endothelial cells. Angiogenesis 2012, 15, 543-554. [CrossRef] [PubMed]

40. Ke, K.; Sul, O.J.; Rajasekaran, M.; Choi, H.S. MicroRNA-183 increases osteoclastogenesis by repressing heme oxygenase-1. Bone 2015, 81, 237-246. [CrossRef] [PubMed]

41. Davis, C.; Dukes, A.; Drewry, M.; Helwa, I.; Johnson, M.H.; Isales, C.M.; Hill, W.D.; Liu, Y.; Shi, X.; Fulzele, S.; et al. MicroRNA-183-5p increases with age in bone-derived extracellular vesicles, suppresses bone marrow stromal (stem) cell proliferation, and induces stem cell senescence. Tissue Eng. Part A 2017. [CrossRef] [PubMed]

42. Stanbrough, M.; Bubley, G.J.; Ross, K.; Golub, T.R.; Rubin, M.A.; Penning, T.M.; Febbo, P.G.; Balk, S.P. Increased expression of genes converting adrenal androgens to testosterone in androgen-independent prostate cancer. Cancer Res. 2006, 66, 2815-2825. [CrossRef] [PubMed]

43. Schuetz, C.S.; Bonin, M.; Clare, S.E.; Nieselt, K.; Sotlar, K.; Walter, M.; Fehm, T.; Solomayer, E.; Riess, O.; Wallwiener, D.; et al. Progression-specific genes identified by expression profiling of matched ductal carcinomas in situ and invasive breast tumors, combining laser capture microdissection and oligonucleotide microarray analysis. Cancer Res. 2006, 66, 5278-5286. [CrossRef] [PubMed]

44. Reynolds, P.A.; Smolen, G.A.; Palmer, R.E.; Sgroi, D.; Yajnik, V.; Gerald, W.L.; Haber, D.A. Identification of a DNA-binding site and transcriptional target for the EWS-WT1(+KTS) oncoprotein. Genes Dev. 2003, 17, 2094-2107. [CrossRef] [PubMed]

45. Satoh, K.; Hata, M.; Shimizu, T.; Yokota, H.; Akatsu, H.; Yamamoto, T.; Kosaka, K.; Yamada, T. $\mathrm{Lib}$, transcriptionally induced in senile plaque-associated astrocytes, promotes glial migration through extracellular matrix. Biochem. Biophys. Res. Commun. 2005, 335, 631-636. [CrossRef] [PubMed]

46. Satoh, K.; Hata, M.; Yokota, H. A novel member of the leucine-rich repeat superfamily induced in rat astrocytes by beta-amyloid. Biochem. Biophys. Res. Commun. 2002, 290, 756-762. [CrossRef] [PubMed]

47. Cooper, P.R.; McLachlan, J.L.; Simon, S.; Graham, L.W.; Smith, A.J. Mediators of inflammation and regeneration. Adv. Dent. Res. 2011, 23, 290-295. [CrossRef] [PubMed]

48. Churov, A.V.; Oleinik, E.K.; Knip, M. MicroRNAs in rheumatoid arthritis: Altered expression and diagnostic potential. Autoimmun. Rev. 2015, 14, 1029-1037. [CrossRef] [PubMed]

49. Nakasa, T.; Shibuya, H.; Nagata, Y.; Niimoto, T.; Ochi, M. The inhibitory effect of microRNA-146a expression on bone destruction in collagen-induced arthritis. Arthritis Rheum. 2011, 63, 1582-1590. [CrossRef] [PubMed]

50. Corrado, A.; Maruotti, N.; Cantatore, F.P. Osteoblast role in rheumatic diseases. Int. J. Mol. Sci. 2017, 18, 1272. [CrossRef] [PubMed]

51. Chang, J.; Jackson, S.G.; Wardale, J.; Jones, S.W. Hypoxia modulates the phenotype of osteoblasts isolated from knee osteoarthritis patients, leading to undermineralized bone nodule formation. Arthritis Rheumatol. 2014, 66, 1789-1799. [CrossRef] [PubMed]

(C) 2017 by the authors. Licensee MDPI, Basel, Switzerland. This article is an open access article distributed under the terms and conditions of the Creative Commons Attribution (CC BY) license (http://creativecommons.org/licenses/by/4.0/). 